\title{
Dragonfly Optimization based Reconfiguration for Voltage Profile Enhancement in Distribution Systems
}

\author{
T. K. Abhiraj \\ Assistant professor, \\ Department of EEE \\ Ilahia School of Science and Technology \\ Pezhakkappilly, Muvattupuzha, Ernakulam, \\ Kerala-685573, \\ India
}

\author{
P. Aravindhababu \\ Professor \\ Electrical Engineering, \\ Annamalai University \\ India
}

\begin{abstract}
Dragonfly Optimization (DO) is a nature inspired optimization technique that imitates the static and dynamic swarming activities of dragonflies. The static swarm possessing smaller number of dragonflies hunts for preys in a small area, while the dynamic swarm with more number of dragonflies travels over long distances; and they represent the exploration and exploitation phases of the DO. This paper applies DO in solving reconfiguration problem of distribution systems with an objective of enhancing the voltage profile. It presents the results of 33 and 69-node distribution systems for illustrating the superiority of the proposed method.
\end{abstract}

\section{General Terms}

distribution systems, optimization

\section{Keywords}

network reconfiguration, dragonfly optimization.

\section{Nomenclature}

$\begin{array}{ll}\text { BBO } & \text { biogeography based optimization } \\ {[C]} & \begin{array}{l}\text { branch-to-node matrix that describes the } \\ \text { topological structure of the distribution } \\ \text { network } \\ \text { dragonfly optimization }\end{array} \\ \text { DO } & \begin{array}{l}\text { DO based reconfiguration method } \\ \text { genetic algorithm }\end{array} \\ \text { GA } & \text { current in branch between nodes-k and -m } \\ i_{k m} & \text { maximum permissible current through branch } \\ i_{k m}^{\text {max }} & \text { between nodes-k and -m } \\ \text { LVM } & \text { lowest node voltage seen in the network } \\ \text { NVD } & \text { net voltage deviations } \\ n n & \text { number of nodes } \\ O S & \text { binary variable that represents status of } j \text {-th } \\ \text { tie switch } & \text { particle swarm optimization } \\ \text { PSO } & \text { voltage profile improvement } \\ \text { VPI } & \text { voltage at node-m } \\ V_{m} & \text { weight coefficients } \\ w_{b} \& w_{c} & \text { a set of limit violated branches }\end{array}$

\section{INTRODUCTION}

Network reconfiguration is a process of changing the topological structure of the distribution networks by altering the status of the open/close switches. Under normal operating conditions, networks are reconfigured to lower the system real power loss. Several mathematical methods such as branchand-bound-type optimization [1], Benders decomposition [2], mixed-integer programming $[3,4]$ etc. have been outlined. Besides, many heuristic approaches for minimizing network loss have been developed [5-7]. These heuristic approaches are usually fast but may not yield the global best configuration. Recently, nature-inspired optimization algorithms such as hyper-cube ant colony optimization [8], bacterial foraging optimization [9], particles swarm optimization [10], artificial immune systems [11], adaptive imperialist competitive algorithm [12], genetic algorithm [13] and biogeography based optimization [14] have been applied for solving reconfiguration problems. The nature-inspired optimization approaches can solve the reconfiguration problems with fewer limitations in the objective space and possess the ability in offering robust solution without using the derivatives of the cost function.

Recently, a Dragonfly Optimization (DO), a meta-heuristic optimization technique imitated from the static and dynamic swarming activities of dragonflies, has been outlined for solving optimization problems by Seyedali Mirjalili [15]. It has been applied to a variety of optimization problems [16-18] and found to yield satisfactory results.

The consumers requires quality power supply with a voltage nearer to nominal voltage. This paper thus aims to develop a new reconfiguration scheme that minimizes the net deviation between the node voltages and the nominal voltage value, using DO. The method is tested on 33- and 69-node radial networks and the results are presented.

\section{PROPOSED METHOD}

This section builds a DO based reconfiguration method (DORM) for enhancing the voltage profile (VP) through minimizing the net voltage deviations (NVD) of Eq. (1) without causing any thermal violations, while retaining the radial structure. The reconfiguration problem can be formulated as an optimization problem [14]

$$
\text { Minimize } \quad N V D=\sum_{j=1}^{n n}\left|V_{j}-1.0\right|
$$

Subject to

$$
\begin{aligned}
& \left|\sum_{j=1}^{n n} C_{1, j}-n n\right|=0 \\
& \left|i_{k m}\right| \leq i_{k m}^{\max }
\end{aligned}
$$


The objective and constraints can be calculated from the load flow solution [19] for a given load data, and status of tie/sectionalizing switches. The above problem can be solved by applying DO. The solution process involves representation of problem variables and formation of a fitness function. The decision variable in the reconfiguration problem is the openswitch numbers. Each dragonfly of the DO is therefore represented to denote the open-switches in vector form as

$$
\text { dragonfly }=\left\lfloor\mathrm{OS}_{1}, \mathrm{OS}_{2}, \cdots \cdots \mathrm{OS}_{n}\right\rfloor
$$

The DO generates real numbers and hence to obtain integer values for open-switches, the real numbers are rounded off to the nearest integer values. The DO searches for optimal openswitches by maximizing a fitness function, which can be tailored from the problem objective and constraint functions as

\section{Maximize}

$$
\text { Fit }=\frac{1}{1+\left(N V D+w_{b} \sum_{m \in \Re}\left(\left|i_{k m}\right|-i_{k m}^{\max }\right)^{2}+w_{c}\left|\sum_{j=1}^{n n} C_{1, j}-n n\right|\right)}
$$

An initial swarm of dragonflies is formed by generating random values within their respective limits. The fitness function is calculated by altering the network topology according to the status of open-switches of each dragonfly; and the exploration and exploitation phases, which represent social interaction of dragonflies in navigating and searching for foods and avoiding enemies, are performed for all the dragonflies in the swarm with a view of maximizing their finesses. The iterative process is continued till convergence. The algorithmic steps of the proposed DORM are summarized below $[15,16]$.

1. Read reconfiguration problem data

2. Choose DO parameters such as swarm size and maximum number of iterations for convergence check.

3. Randomly generate a swarm of dragonflies that represent open switches

4. Generate the initial velocity vector, food source and enemy.

5. Set iteration counter $k=0$

6. $k=k+1$

7. For each dragonfly,

a. Obtain the details of open-switches

b. Alter the distribution network according to the details of open-switches

c. Carryout distribution power flow and then compute fitness function using Eq. (5)

8. Update the food source and enemy

9. For each dragonfly,

a. Obtain the status of open switches for each dragonfly

b. Compute the Euclidean distance of each dragonfly with other members in the swarm and select the number of neighbours.

c. Based on the number of neighbours, update the velocity and position vectors.

10. Check for convergence. If converged, go to next step. Else, go to step (6).

11. The best food source represents optimal open-switches.

12. Stop.

\section{NUMERICAL RESULTS}

The DORM has been applied on 33 and 69 node distribution systems [20,21]. The 33 node network, operating at $12.66 \mathrm{kV}$ with net loads of $3715 \mathrm{~kW}$ and $2300 \mathrm{kVar}$, contains 5 normally opened switches and 32 normally closed switches. While 69 node network, operating at $12.66 \mathrm{kV}$ with network load of $3802.19 \mathrm{~kW}$ and $2694.60 \mathrm{kVar}$, possesses 5 tie-loops. The results of the DORM have been compared with those of the BBO, GA and PSO based methods [14].

\begin{tabular}{|c|c|c|c|c|}
\hline & & Open-switches & NVD & LVM \\
\hline \multirow{5}{*}{$\begin{array}{l}33 \text { node } \\
\text { system }\end{array}$} & $\begin{array}{c}\text { Initial } \\
\text { Configuration }\end{array}$ & $33,34,35,36,37$ & 1.8046 & 0.9038 \\
\hline & DORM & $7,9,14,36,28$ & 1.0619 & 0.9378 \\
\hline & $\mathrm{BBO}$ & $7,14,9,17,28$ & 1.0668 & 0.9327 \\
\hline & GA & $33,34,10,17,28$ & 1.0927 & 0.9313 \\
\hline & PSO & $33,34,11,36,28$ & 1.0865 & 0.9319 \\
\hline \multirow{5}{*}{$\begin{array}{l}69 \text { node } \\
\text { system }\end{array}$} & $\begin{array}{c}\text { Initial } \\
\text { Configuration }\end{array}$ & $69,70,71,72,73$ & 1.8370 & 0.9092 \\
\hline & DORM & $14,58,64,69,70$ & 0.7846 & 0.9383 \\
\hline & $\mathrm{BBO}$ & $14,57,64,69,70$ & 0.8273 & 0.9382 \\
\hline & GA & $69,14,70,56,61$ & 0.9189 & 0.9495 \\
\hline & PSO & $69,14,70,58,62$ & 0.8421 & 0.9483 \\
\hline
\end{tabular}

Table.1 Summary of Results for 33 node network

The status of open-switches, NVD and lowest voltage magnitude (LVM) before and after reconfiguration of 33 and 69 node network are given in Table-1.

It is very clear from the results that the proposed DORM reduces the initial NVD of 1.8046 to 1.0619 through opening the tie-switches in lines 7, 9, 14, 36 and 28, which leads to $\% \mathrm{VP}$ improvement (\%VPI) of $41.16 \%$, while the BBO, GA and PSO offer $40.88 \%, 39.45 \%$ and $39.79 \%$ of $\%$ VPI for 33 node system for 33 node system. In case of 69 node system, the proposed DORM opens the tie-switches of $14,58,64,69$ and 70 and reduces the initial NVD of 1.8370 to 0.7846 , while the BBO, GA and PSO can reduce the NVD to 0.8273 , 0.9189 , and 0.8421 respectively.

The LVM of all the four methods is found to lie in between the lower and upper limits. Similar kind of improvement in performances can be observed from the results of 69 node system. The VP for 33 and 69 node systems before and after reconfiguration is graphically plotted in Fig.A.1 and A.2 respectively. It is seen from the figure that there is significant improvement in the VP after reconfiguration.

The above results and discussions clearly indicate that the proposed DORM offers a better configuration that reduces the NVD and offers a good VP.

\section{CONCLUSIONS}

Dragonfly Optimization (DO), inspired from the static and dynamic swarming activities of dragonflies, has been applied for reconfiguring the distribution networks with an objective of improving the VP, unlike the usual process of lowering the system real power loss. This DO optimally selects the open- 
switches based on a fitness function built from the problem objective function and constraints. The results on two test systems have exhibited that the proposed DORM is able to provide enhanced VP without any extra infrastructural facilities. The suggested method is suitable for practical application on networks of any size. The suggested method can be modified to enhance voltage stability of the distribution networks.

\section{ACKNOWLEDGMENTS}

The authors gratefully acknowledge the authorities of Annamalai University and Ilahia School of Science and Technology for the facilities offered to carry out this work.

\section{APPENDIX}

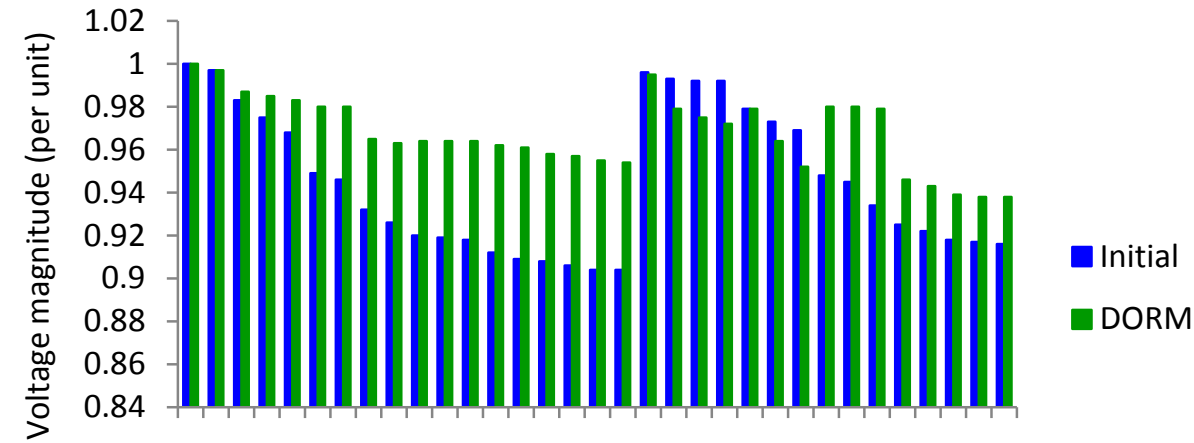

$\begin{array}{lllllllllllllllll}1 & 3 & 5 & 7 & 9 & 11 & 13 & 15 & 17 & 19 & 21 & 23 & 25 & 27 & 29 & 31 & 33\end{array}$

Node Number

Fig. A.1 VP of 33 node network

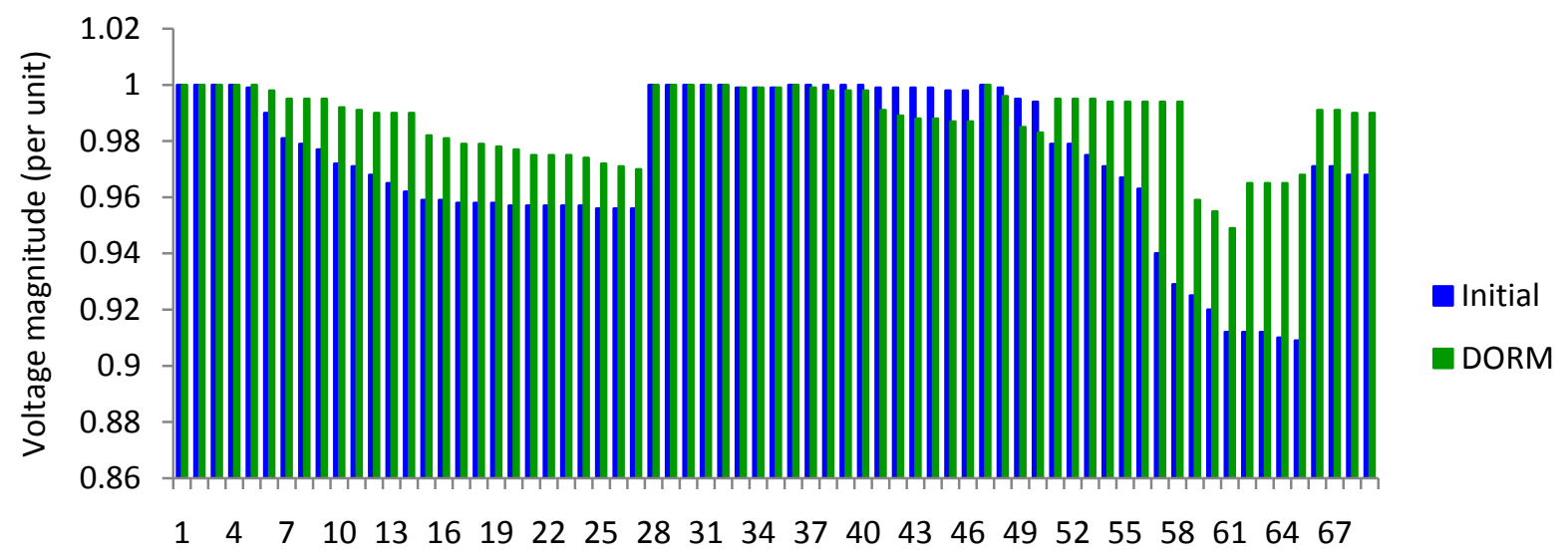

Node Number

Fig. A.2 VP of 69 node network

\section{REFERENCES}

[1] Merlin A and Back H. (1975). Search for a minimal loss operating spanning tree configuration for an urban power distribution system, Proc of the power systems computation conf (PSCC): 1-18.

[2] H. M. Khodr and J. Martinez-Crespo. (2009). Integral methodology for distribution systems reconfiguration based on optimal power flow using benders decomposition technique, IET Gen. Trans. \& Dist., 3(6): $521-534$.

[3] R. A. Jabr, R. Singh and B. C. Pal. (2012). Minimum loss network reconfiguration using mixed-integer convex programming, IEEE Trans on Power Systems, 27 (2): $1106-1115$.
[4] J. A. Taylor and F. S. Hover. (2012). Convex models of distribution system reconfiguration, IEEE Trans. On Power Systems, 27(3): 1407-1413.

[5] Civanlar S, Grainger J and Yin H, Lee S .(1988). Distribution feeder reconfiguration for loss reduction, IEEE Trans Power Delivery, 3(3): 1217-1223.

[6] Goswami S and Basu S. (1992). A new algorithm for the reconfiguration of distribution feeders for loss minimization, IEEE Trans Power Delivery, 7(3):14821491.

[7] Shirmohammadi D and Hong H. (1989). Reconfiguration of electric distribution networks for resistive line loss reduction, IEEE Trans Power Delivery, 4(2):1492-1498.

[8] A.Y. Abdelaziz, R. A. Osama and S. M. El-Khodary. (2012). Reconfiguration of distribution systems for loss 
reduction using the hyper-cube ant colony optimization algorithm, IET Gen. Trans. \& Dist., 6(2): 176-187.

[9] K. Sathish Kumar and T. Jayabarathi. (2012). Power system reconfiguration and loss minimization for distribution systems using Bacterial Foraging optimization algorithm, Int. J. Electr. Power Energy Syst, 36(1): 13-17.

[10] M. R. Andervazh, J. Olamaei and M. R. Haghifam. (2013). Adaptive multi-objective distribution network reconfiguration using multi-objective discrete Particles Swarm Optimisation algorithm and graph theory, IET Gen. Trans. \& Dist., 7(12): 1367-1382.

[11] L. W. de Oliveira, E. J. de Oliveira, F. V. Gomes, I. C. Silva Jr, A. L. M. Marcato and P. V. C. Resende. (2014). Artificial Immune Systems applied to the reconfiguration of electrical power distribution networks for energy loss minimization, Int. J. Electr. Power Energy Syst., 56: 6474.

[12] S. H. Mirhoseini, S. M. Hosseini, M. Ghanbari and M. Ahmadi. (2014). A new improved adaptive imperialist competitive algorithm to solve the reconfiguration problem of distribution systems for loss reduction and voltage profile improvement, Int. J. Electr. Power Energy Syst., 55: 128-143.

[13] N. Gupta, A. Swarnkar and K. R. Niazi. (2014). Distribution network reconfiguration for power quality and reliability improvement using Genetic Algorithms, Int. J. Electr. Power Energy Syst., 54: 664-671.

[14] S. Aruul Vizhiy and R.K.Santhi. (2016). New Reconfiguration Method for Improving Voltage Profile of Distribution Networks," International Journal of Computer Application, 135(7) : 25-29.
[15] Seyedali Mirjalili., Dragonfly algorithm, 2015: A new meta-heuristic optimization technique for solving singleobjective, discrete and multi-objective problems, Neural Comput and Applic. DOI. 10.1007/s00521-015-1920-1.

[16] Dharmendra Tiwari, Nikhil Pachauri, Asha Rani, Vijander Singh, 2016. Fractional Order PID (FOPID) Controller based Temperature Control of Bioreactor, Proceedings of International Conference on Electrical, Electronics, and Optimization Techniques (ICEEOT).

[17] Hamdy, M., Nguyen, AT., and Hensen, J.L.M., 2016. A performance comparison of multi-objective optimization algorithms for solving nearly-zero-energy-building design problems, Energy and Buildings. http://dx.doi.org/10.1016/j.enbuild.2016.03.035.

[18] Rakoth Kandan Sambandam and Sasikala Jayaraman. (2016). Self-adaptive dragonfly based optimal thresholding for multilevel segmentation of digital images, Journal of King Saud University-Computer and Information Sciences, http://dx.doi.org/10.1016/j.jksuci.2016.11.002.

[19] P.Aravindhababu, S.Ganapathy and K.R.Nayar. (2001). A novel technique for the analysis of radial distribution systems, International Journal of Electric Power and Energy Systems, ISSN:0142-0615, 23(3): 167-171

[20] Baran M and Wu F. (1989). Network reconfiguration in distribution systems for loss reduction and load balancing, IEEE Trans on Power Delivery, 4(2): 14011407.

[21] Kashem M, Ganapathy V and Jasmon G (2001) A geometrical approach for network reconfiguration based loss minimization in distribution systems, Int $\mathrm{J}$ Elect Power Energy Syst, 23(4): 295-304. 